\title{
The impact of river fragmentation on the population persistence of native and alien mink: an ecological trap for the endangered European mink
}

\author{
Iñigo Zuberogoitia $\cdot$ Hanna Zalewska $\cdot$ Jabi Zabala $\cdot$ Andrzej Zalewski
}

Received: 4 May 2012/Accepted: 22 November 2012/Published online: 2 December 2012

(C) The Author(s) 2012

\begin{abstract}
The genetic diversity of feral and ranch American mink was studied in order to detect gene flux among rivers, investigate the processes of invasion, and determine the possible effects of river barriers. Tissue samples of 78 feral American mink from 5 different river catchments and 18 ranch mink, collected between 2007 and 2011 in Biscay, northern Spain, were genotyped at 21 microsatellite loci. Lack of genetic differentiation of feral mink among the sites and high differentiation between feral and ranch mink was suggested. These results confirm that the mink population established on Butrón River at the beginning of the 1990s may be the origin of almost all the feral mink population within the study area. Additionally, the occurrence of American and European mink was used to analyse the effect of fragmentation on the population viability. The size and composition of the home range of male European mink was considered to model minimum viable units for presence/absence. Forty-two minimum viable units were randomly distributed among rivers in order to analyse the effect of fragmentation on mink occurrence. Barriers were mapped and classified as slight, moderate or absolute, depending on the effect on mink movement, and were introduced into the models. The presence of European and American mink depended on the non-fragmented main river stretches and the number of tributaries free from barriers. Results showed that fragmented rivers can be temporarily occupied but the likelihood of death means that these areas are only sink patches for mink.
\end{abstract}

Keywords Connectivity · Gene flow · Habitat fragmentation · Invasive alien species · Mink farming · River barriers

Electronic supplementary material The online version of this article (doi:10.1007/s10531-012-0410-3) contains supplementary material, which is available to authorized users.

I. Zuberogoitia $(\bowtie)$

Estudios Medioambientales Icarus, Pintor Sorolla 6, $1^{\circ}$ C, 26007 Logroño, Spain e-mail: Zuberogoitia@icarus.es

H. Zalewska · A. Zalewski

Mammal Research Institute, Polish Academy of Sciences, 17-230 Białowieża, Poland

J. Zabala

Sebero Otxoa 45, 5 B., 48480 Arrigorriaga, Bizkaia, Spain 


\section{Introduction}

Habitat loss and degradation are the greatest extinction threats to biodiversity in a variety of ecosystems and taxonomic groups (Jager et al. 2006; Fischer and Lindenmayer 2007). The process of habitat degradation implies the gradual deterioration of habitat quality and can generate a pattern of variation in patch quality for a given species (Mortelliti et al. 2010). In degraded habitat a species may decline, occur at a lower density, or be unable to breed, thus the area becomes an "ecological trap" to which individuals of a species are attracted, but in which they cannot reproduce (Felton et al. 2003; Battin 2004; Hazell et al. 2004). Fragmentation makes the difference between persistence and extinction, since longer dispersal distances to find territories increases movement-related mortality, territories include lower quality habitat, which elevated habitat-related mortality and Alee effects (failure to find mates) reduce births (Jager et al. 2006). Habitat isolation can have a negative effect not only on the dispersal of juveniles (by decreasing population connectivity) but also, and to an even greater extent, on the day-to-day movements of a given territorial species (Fahrig 2003; Fischer and Lindenmayer 2007; Zabala et al. 2007b; Zalewski et al. 2009). A reduction in, or even the breaking of connectivity can have substantial consequences for population demography and genetic structure due to inbreeding, genetic drift, founder effect or other stochastic processes (Frankham et al. 2002). Thus, it is expected that a fragmented habitat can be temporarily occupied by a dispersing individual but the survival likelihood is negatively correlated with the time period spent in the area (see Fischer and Lindenmayer 2007).

For aquatic and semi-aquatic species, rivers and their adjoining riparian zones are considered to be the most important habitat and corridors (Malanson 1993; Virgos 2001). However, rivers are increasingly fragmented by dams and other artificial structures, disrupting the natural dispersal pathways which, to date, have mainly been described for migratory fish (Petts 1984). There are no published data regarding the potential effect of fragmentation on semi-aquatic mammals, although some authors have suggested the possible importance of fragmentation with regard to population persistence (Lodé and Peltier 2005). Many riparian mammals may possess the ability to elude dams or other anthropogenic barriers by moving along the riverside, out of the waterway (see Kruuk 2006), but how it affects their spacing pattern, survival or reproduction is still an open question. The European mink, Mustela lutreola, and American mink, Neovison vison, are two mammal predators which inhabit the riparian zone. Both species are similar in size and they occupy a similar ecological niche (Macdonald et al. 2002; Sidorovich et al. 2010). Following the introduction of the American mink to Europe both species occurred in sympatry and the American mink negatively affected the population of European mink, thus reducing their abundance (Macdonald et al. 2002). The population of European mink decreased in the whole of Europe, probably due to competition between both species and/ or the intraguild predation effect (see Maran et al. 1998) but perhaps also because of habitat changes in the river ecosystems (Lodé et al. 2001).

We analysed the effect of habitat fragmentation on these two species, the native endangered species (European mink) and the invasive species (American mink). Both have similar habitat requirements and hence should be affected in a similar way by habitat fragmentation, although the more generalist habits, both in diet and habitat preferences, of American mink (see i.e. Garin et al. 2002a; Zuberogoitia et al. 2006; Zabala et al. 2006, 2007a, b; Melero et al. 2008) may influence in a higher resilience to fragmentation. We used occupancy data in order to analyse suitable habitat for these species but, in contrast to previous papers (i.e. Melero et al. 2008; Schüttler et al. 2010; Garin et al. 2002a, b; Zabala 
et al. 2003; 2007a, b; Zabala and Zuberogoitia 2003), we did not consider classical habitat descriptors but instead used variables related to habitat fragmentation. We hypothesised that large numbers of barriers across rivers (such as dams, highways, railway crossings etc.) increase fragmentation and turn continuous habitat into non-favourable patches, thus affecting the occurrence of both species and their genetic structure. The alternative hypothesis was that, despite the habitat fragmentation, mink can disperse between patches and there is no genetic structure (the gene flow is continuous) and that both mink occurred in patches, with no relation being shown to the number of barriers.

\section{Methods}

Study area

The study was conducted in Biscay, Basque Country, Spain (Fig. 1). Biscay covers an area of 2,236 $\mathrm{km}^{2}$ and its population is approximately 1.2 million inhabitants. The landscape is hilly and rugged and altitudes range from 0 to 1,475 m.a.s.l. (Gorbea Peak). The climate is oceanic, with annual rainfall ranging between 1,200 and 2,200 $\mathrm{mm}$ and annual average temperatures varying from 12.8 to $18.4{ }^{\circ} \mathrm{C}$. Winters are mild and there is no summer drought. There are several small, short, fast-flowing catchments running into the Bay of Biscay. The widest streams reach $15 \mathrm{~m}$ across but most of the main streams are between 6 and $10 \mathrm{~m}$ wide. Major infrastructures such as roads, railways and villages run along the valleys, parallel to rivers, and some riverbanks have been altered and partially canalised. The upper parts of the streams are the least modified and gallery forests of alder (Alnus glutinosa), ash (Fraxinus excelsior) and willow (Salix spp.) are commonly found on the banks. The middle stretches of the rivers are the most diverse, varying between wellpreserved zones, areas which have been forested with exotic plantations, disturbed areas with heliophytic formations, and parts which have been canalised. The lower reaches are the most modified, with forested areas being rare and, with the exception of some scarce, well-preserved stretches, the riverbank vegetation here is mainly composed of brambles (Rubus spp.) or is absent (Navarro 1980). Several of the lower reaches are deeply canalised where they pass through urban areas. In rural, low-lying areas, the land is mostly devoted to forest cultures, mainly exotic Pinus radiata and Eucalyptus spp., which occupy more than half of the surface area of Biscay (Department of Environment and Land Ordination 2001).

\section{Mink presence/absence data}

Mink data were obtained from a systematic control/eradication program developed from 2007 onwards. From 2007 to 2011 we set 16,566 trap-nights in 11 river catchments during winter, following a regular trapping protocol (see Zuberogoitia et al. 2010 for further details). Over this period we captured 120 American mink from six of the catchments and 11 European mink from three catchments (Fig. 2). European mink were released immediately at the trapping site and American mink were transported to the Wildlife Rehabilitation Centre of Bizkaia and humanely killed. Data regarding the presence of both mink species was also obtained from other records (road casualties, occasional trapping, photographed mink and poaching). All the trapping, handling and culling was conducted with the permission of regional wildlife authorities and in line with the laws and ethical protocols governing wildlife management. 


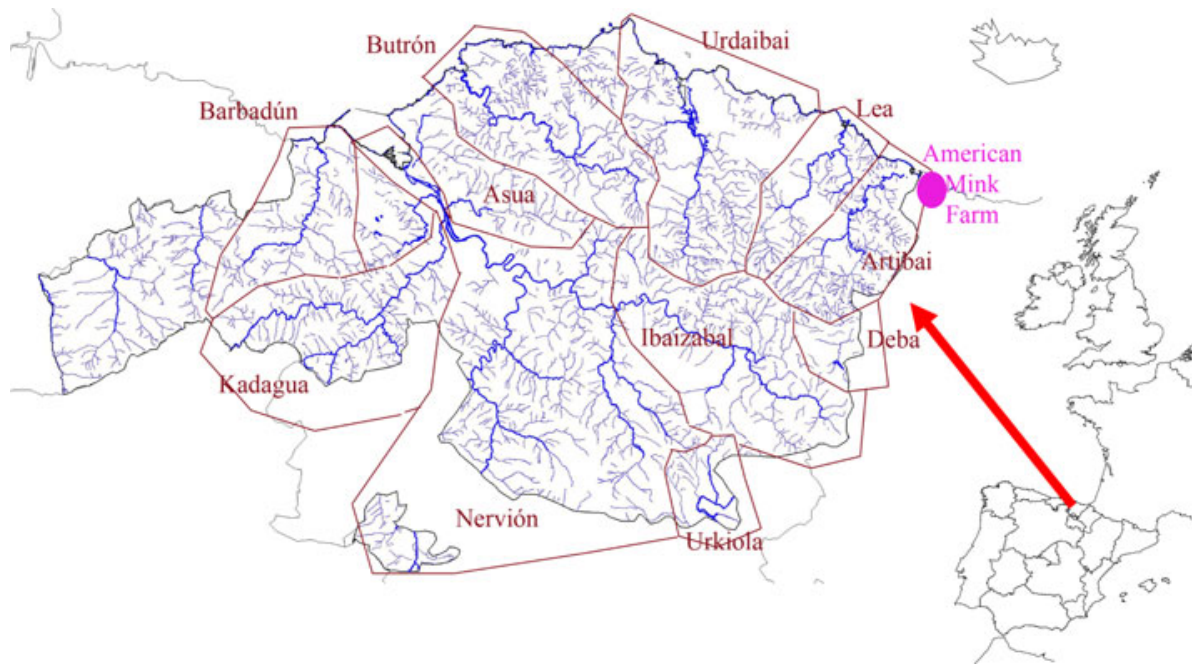

Fig. 1 The main river basins (polygons) selected for the current study in Biscay (Basque Country, Northern Iberian Peninsula). The pink dot shows the location of the closest active American mink farm. (Color figure online)

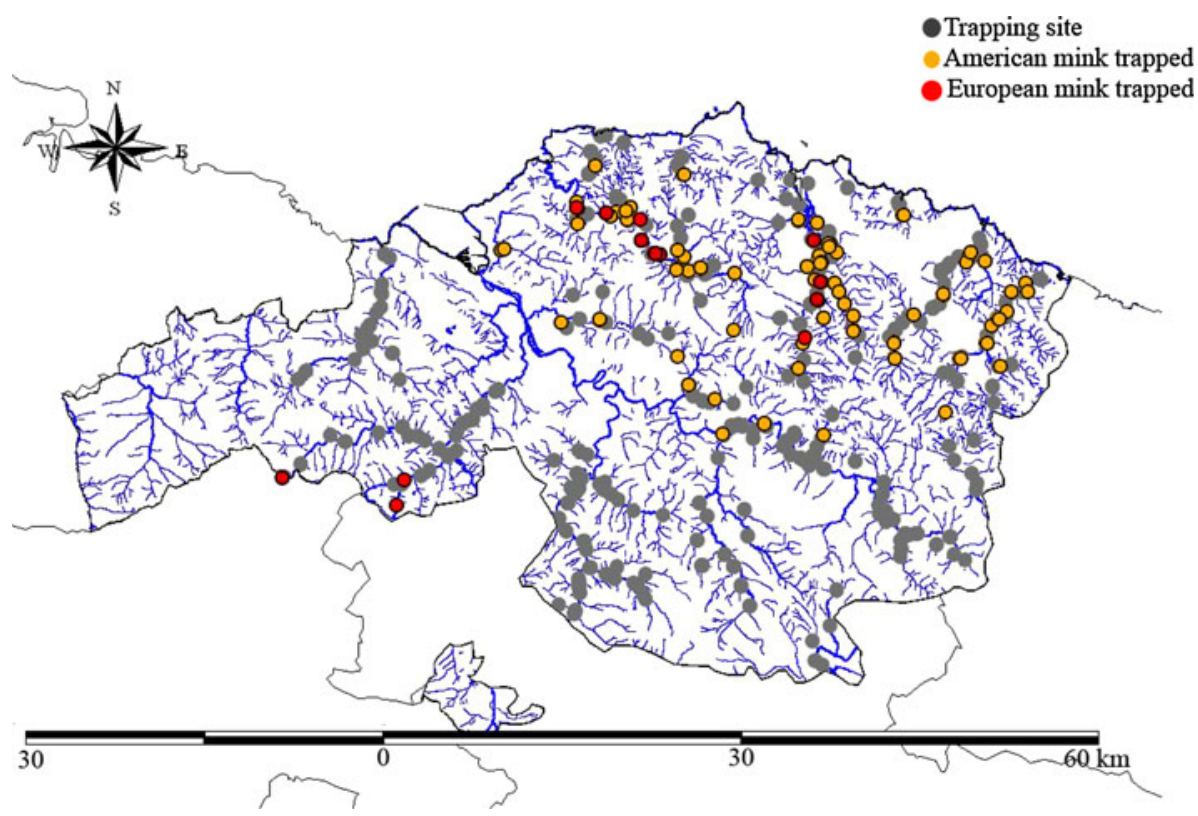

Fig. 2 Trapping sites (grey dots), American mink captured and culled (orange dots) and European mink captured and released (red dots) between 2007 and 2011. (Color figure online)

Genetics analysis

In the case of trapped American mink, a total of 78 tissue samples were collected from 5 river catchments (Table 1; Fig. 1). Additionally, we collected muscle tissue from 18 ranch 
Table 1 Genetic diversity indices of samples of American mink genotyped at 20 unlinked microsatellite loci from Biscay, Basque Country (N Spain)

\begin{tabular}{lrllllllll}
\hline Sampling site & $N$ & $A$ & Ar & $A_{\text {private }}$ & $N_{\mathrm{e}}$ & $H_{\mathrm{O}}$ & $H_{\mathrm{E}}$ & Overall $F_{\mathrm{IS}}$ & HWE $(P$ value $)$ \\
\hline Ibaizabal & 9 & 3.7 & 3.6 & 0.05 & 2.58 & 0.598 & 0.552 & -0.024 & 0.8633 \\
Butron & 26 & 4.0 & 3.4 & 0 & 2.54 & 0.547 & 0.562 & 0.046 & 0.0877 \\
Urdaibai & 20 & 4.0 & 3.4 & 0.1 & 2.54 & 0.575 & 0.563 & 0.005 & 0.5007 \\
Lea & 11 & 3.8 & 3.6 & 0 & 2.64 & 0.573 & 0.579 & 0.058 & 0.5973 \\
Artibai & 12 & 4.7 & 4.1 & 0.2 & 2.94 & 0.567 & 0.602 & 0.101 & 0.0554 \\
Ranch & 18 & 5.9 & 4.9 & 1.4 & 3.64 & 0.679 & 0.692 & 0.047 & 0.1034
\end{tabular}

See Fig. 1 and the text for the locations and names of the sample sites. $N$ number of analysed samples, $A$ mean number of alleles per locus (direct count), $A r$ allelic richness estimated by rarefaction based on a minimum sample size $n=9, A_{\text {private }}$ number of private alleles, $N_{\mathrm{e}}$ number of effective alleles $\left(1 / \Sigma p i^{2}\right), H_{\mathrm{O}}$ observed heterozygosity, $H_{\mathrm{E}}$ unbiased expected heterozygosity

mink: from the mink farm located to the east of the feral mink study area $(7 \mathrm{~km}$ from the River Artibai, Fig. 1). All tissue samples were placed in concentrated alcohol and stored at $-20{ }^{\circ} \mathrm{C}$ prior to DNA extraction.

We extracted DNA from tissue samples using a DNeasy Blood and Tissue Kit (Qiagen), following the manufacturer's instructions. Twenty-one microsatellite loci developed for mink were used to genotype individuals: Mvis002, Mvis027, Mvis072, Mvis075, Mvis099, Mvis192, Mvi54, Mvi57, Mvi111, Mvi114, Mvi219, Mvi232, Mvi586, Mvi1006, Mvi1016, Mvi1302, Mvi1321, Mvi1341, Mvi2243, Mvi4001, Mvi4058 (O'Connell et al. 1996; Brusgaard et al. 1998; Fleming et al. 1999; Vincent et al. 2003; Farid et al. 2004; Anistoroaei et al. 2006). Microsatellites were amplified in five multiplex reactions prepared using a Multiplex PCR Kit (QIAGEN) following the manufacturer's instructions. Reaction mixtures contained approximately $1 \mu \mathrm{l}$ of template DNA in a total volume of $5.0 \mu \mathrm{l}$. The thermal cycle, performed in a DNA Engine Dyad Peltier Thermal Cycler (BIO-RAD), consisted of an initial denaturalisation step at $95{ }^{\circ} \mathrm{C}$ for $15 \mathrm{~min}$, followed by 30 cycles at $94{ }^{\circ} \mathrm{C}$ for $30 \mathrm{~s}, 60{ }^{\circ} \mathrm{C}$ for $1 \mathrm{~min} 30 \mathrm{~s}$ and $72{ }^{\circ} \mathrm{C}$ for $1 \mathrm{~min}$ and then a final extension period of $30 \mathrm{~min}$ at $60{ }^{\circ} \mathrm{C}$. The amplified fragments were resolved by electrophoresis using the ABI 3100 Genetic Analyzer (Applied Biosystems) using GeneMarker 1.85.

Estimates of pairwise linkage disequilibrium and departures from the Hardy-Weinberg equilibrium for each pair of loci in each population were calculated using GenePop on the Web version 4.0.10 (Raymond and Rousset 1995); Bonferroni's correction was applied to multiple comparisons. Evaluations of the presence of null alleles were performed using MicroChecker version 2.2.3 (Van Oosterhout et al. 2004). Loci that consistently departed from equilibrium, showed linkage equilibrium or evidence of null alleles were removed from further analyses. The genetic variability of each locus within each feral population and also in ranch mink was estimated as the mean allele number (A), mean number of private alleles $\left(A_{\text {private }}\right)$, number of effective alleles $\left(N_{\mathrm{e}}\right)$, heterozygosity $\left(H_{\mathrm{O}}\right)$ and expected heterozygosity $\left(H_{\mathrm{E}}\right)$ using FSTAT (Goudet 1995) and GenAlex version 6 (Peakall and Smouse 2006). The mean number of alleles per locus is expected to be sensitive to sample size, therefore estimates of the expected allele number per locus and mink origin were corrected for unequal sample size $(\mathrm{Ar})$. The inbreeding coefficient $\left(F_{\text {IS }}\right)$ and potential deviation from the Hardy-Weinberg equilibrium and linkage equilibrium for each locus and site were tested using the randomisation test in GENEPOP 3.4 (Raymond and Rousset 1995). 
We used a range of different analytical approaches for identifying genetic differentiation across samples of feral and ranch American mink. Population genetic structure was detected by determination of $F_{\mathrm{ST}}$ (Fixation Index) levels among predefined populations using FSTAT 2.9.3 software (Goudet 1995) as well as the recently developed, alternative measure of genetic differentiation $D_{\text {est }}$ (Jost 2008), using the software SMOGD 1.2.5 (Crawford 2010). Cryptic genetic structure of American mink was assessed using STRUCTURE 2.2 software (Pritchard et al. 2000). The greatest rate of change of the likelihood function with respect to $K(\Delta K)$ was used to find the most likely $K$ (Evanno et al. 2005). In the first round of STRUCTURE analyses, we searched for the number of genetically different populations using the entire data set, including feral and ranch mink. This method usually detects only the uppermost level of genetic structure (Evanno et al. 2005). For each round of STRUCTURE analysis, we used the model which assumed no prior information about the population and the admixture model with correlated allele frequency parameters $(\lambda=1)$, and a burn-in phase of 500,000 interactions followed by a run phase of 500,000 interactions. Posterior probability values for the number of populations $(\mathrm{K})$, ranging from 1 to 7 , were calculated from 10 independent runs, to establish consistency. To assess the number of ranch mink in the feral population we estimated the proportion of individuals with membership $\mathrm{q} \geq 0.8$ in the first level of structure analysis.

To assess the presence of genetic isolation-by-distance, we tested correlations between genetic distance and the geographic distances (Euclidean distance) between all pairs of individuals of feral mink. Geographic distances between pairs of individuals were calculated as straight-line-distances. The Mantel test, using GenAlEx version 6.4 (Peakall and Smouse 2006), was performed with significance based on 1,000 matrix permutations. To assess the presence of spatial genetic structure at the level of individuals, analyses were carried out using autocorrelation functions incorporated into GenAlEx version 6.4 (Peakall and Smouse 2006) for multilocus data (20 loci), following the method of Smouse and Peakall 1999). The autocorrelation coefficients (r) were calculated using two pair wise matrices: 1) squared genetic distances and 2) geographical distances, and represented as a correlogram. The geographical distances were calculated as Euclidean distances between samples. For each analysis, we used 1,000 permutations to test the hypothesis of no spatial genetic structure, and 1,000 bootstraps to estimate $95 \%$ confidence intervals for $r$ for a given geographical distance (Peakall et al. 2003).

We did not analyse European mink samples due to the lack of enough samples.

Modelling analysis units for presence/absence

In mustelids the home range of males is greater than that of females and one male home range encompasses those of several females (see i.e. Moors 1980). Moreover, the male home range of European mink is larger than that of American mink (Garin et al. 2002a, b; Zabala et al. 2007b). Therefore, we consider that the home range of the male European mink would be the minimum viable area required to preserve the species. In one viable area one male and several females of European mink, and/or American mink, may appear.

We obtained home ranges, and the proportion of main river and tributaries in mink territories, after radio-tracking eight males and three females of European mink and five males and five females of American mink, in three different catchments (for more details see Garin et al. 2002b; Zabala et al. 2007b; and supplementary material).

We randomly placed 42 independent points in the rivers of the study area. These points were located only at sites where we had previously set traps during the 2007-2011 trapping period. We then created buffer areas of $3 \mathrm{~km}$ radius (which was previously checked to 
Table 2 Average home range (SD) and average percentage of home range in tributaries (SD) of radiotracked European and American mink in Biscay

\begin{tabular}{llcl}
\hline Species—sex & $N$ & Home range $(\mathrm{km})$ & Percentage of home range in tributaries $(\%)$ \\
\hline European mink-male & 7 & $13.13(2.84)$ & $42.34(28.66)$ \\
European mink-female & 3 & $3.40(2.76)$ & $58.10(38.54)$ \\
American mink-male & 3 & $7.05(7.78)$ & $27.67(31.55)$ \\
American mink-female & 4 & $4.92(3.79)$ & $53.78(15.41)$ \\
\hline
\end{tabular}

$N$ number of radio-tracked individuals (adapted from Garin et al. 2002b; Zabala et al. 2007b)

encompass the average length of rivers, see supplementary material) around these points in order to model the ideal home range area of a male European mink: each buffer area contained an equivalent of $13 \mathrm{~km}$ of rivers, of which $42.34 \%$ were tributaries (Table 2). Buffer areas did not overlap.

\section{Mapping barriers in rivers}

During the 2007-2011 period we inspected the rivers in Bizkaia in order to detect every barrier which could affect river connectivity. Fragmentation structures were included in a Geographic Information System (GIS, Arcview 3.2.). We considered three types of barriers with regard to the hypothetical effect on the mink home ranges and their displacement along the river:

(1) Slight barrier: Those artificial structures (concrete walls, rubble walls, river dams, underpasses) which allow mink to move up and down the river but create zones where vegetation and resting or refuge sites are not available. Mink can pass these structures by walking or swimming, but each time they do so they risk their lives due to the high level of exposition towards predators (feral cats, dogs, foxes, raptors, owls, and others). These types of structures can affect only a few meters of riverbank or can be spread over several kilometres and the risk is directly proportional to the length of the barrier.

(2) Moderate barrier: Those artificial structures which affect river connectivity, mainly between small streams and main rivers, i.e. drainage pipes; inadequate wildlife crossings below roads, highways and railways; and pipes below urbanized areas, which all require mink to enter them in order to move along the river. In these cases, mink could enter the pipes and crossings and utilise them to get past the barriers (although we found that radio-tracked mink never entered these types of structures). Alternatively they could come out of the river and cross roads or other structures, although this strategy involves serious risk of being killed on the roads or by predators.

(3) Absolute barrier. Some artificial structures such as concrete river banks, drainage pipes and pipes below urbanized areas, which include vertical water jumps made of concrete. These allow mink to move downstream but it is impossible for them to jump back up. In the case of absolute barriers there are no possibilities of exiting the river due to the existence of other impediments. 
Model definition

We considered as dependent variable the capture/non capture of European and American mink in the 42 minimum viable areas during the 2007-2011 trapping period.

Independent variables considered for analysis were: (1) the length of the main river (streams between 4 and $15 \mathrm{~m}$ in width), considering only those streams which are represented on the 1:50,000 and 1:25,000 scale maps (http://www1.euskadi.net/cartografia/ see in Zabala et al. 2010); (2) the length of the largest stretch of the main river free from barriers; (3) the number of river dams in the main stream which could be considered as real barriers to mink movement (little dams or those with fish scales were not considered); (4) the number of tributaries affected by slight river barriers; (5) the number of tributaries affected by moderate river barriers; (6) the number of tributaries affected by absolute river barriers; (7) the number of tributaries which were free from barriers. We only considered tributaries of at least one $\mathrm{km}$ in length and $1.5 \mathrm{~m}$ in width, represented on the 1:10,000 scale maps (http://www1.euskadi.net/cartografia/).

\section{Statistics}

Univariate tests for differences between minimum viable units (with or without mink) were computed using $t$-tests. When the assumption of normality was violated, comparisons were made with Mann-Whitney's test (Zar 1996). Significance level was set at $P<0.05$. The combined effect of the habitat factors on the likelihood of buffer areas being occupied or not was assessed by means of a Generalized Linear Models (GLM) analysis, with presence/ absence as a binary response variable with a logit link function. We compared all the areas occupied by a species with the unoccupied areas, in order to model factors associated with the settlement of each species. Two pairs of variables were highly intercorrelated: Length of main river and longest un-fragmented stretch $(r=0.52, P<0.001)$ and number of tributaries free from barriers and number of tributaries with absolute barriers $(r=-0.68$, $P<0.001)$. We combined variables into nine competing models: model 1 was the most general and included all variables, model 2 and 3 excluded correlated variables, and the others excluded variables following backward procedures. We sequentially removed nonsginificant terms from the model, so as to get a minimum adequate model. Simultaneously, we carried out an information-theoretic approach, through and AIC $c$-based model selection (corrected for small samples, Burnham and Anderson 2002). Values and parameter estimates are reported with their standard errors.. We used AICc model selection criteria to avoid over-fitting of the model (Burnham and Anderson 2002) and therefore ensure wider applicability of the results. Statistical analyses were performed by running SPSS v18 (SPSS INC., Chicago, IL, USA)

\section{Results}

Genetic variation and structure of American mink

Significant signs of null alleles were found in one loci (Mvi1302) therefore, since null alleles may lead to misinterpretation of the data and incorrect biological conclusions, we excluded this loci from further analysis. Fifty-seven of 1140 pairwise loci Fisher exact probability tests of deviation from genotypic equilibrium were significant at $P<0.05$ but these were scattered randomly across locus pairs. All 20 microsatellite loci were 
polymorphic and overall a total of 134 alleles were found, with an overall mean of 6.7 $(\mathrm{SE} \pm 0.41)$. The total number of alleles per locus ranged from 2 (Mvis002) to 10 (Mvi1016). The mean number of alleles (A) per feral mink within the sampling sites ranged from 3.7 to 4.7 and was smaller than in ranch mink (5.9; Table 1). Similarly, the allelic richness $(\mathrm{Ar})$, the number of private alleles $\left(A_{\text {private }}\right)$ and the number of effective alleles $\left(N_{\mathrm{e}}\right)$ were lower in feral mink than in ranch mink (Table 1). All sampling sites showed intermediate values of heterozygosity and $H_{\mathrm{O}}$ and $H_{\mathrm{E}}$ per site ranged from 0.547 to 0.598 and from 0.552 to 0.630 respectively, and both values were lower than in ranch mink $\left(H_{\mathrm{O}}=0.679\right.$ and $H_{\mathrm{E}}=0.692$; Table 1$)$. All sampling sites demonstrated non-significant deviation from Hardy-Weinberg expectations after Bonferroni correction.

Lack of genetic differentiation of feral mink among sites and high differentiation between feral and ranch mink was suggested by pairwise $F_{\mathrm{ST}}$ and $D_{\text {est }}$ values (Table 3 ). The $F_{\mathrm{ST}}$ values ranged from 0.002 to 0.051 and most values did not differ significantly after sequential Bonferroni correction, suggesting a lack of significant differentiation among sites. Exceptions were the site pairs Artibai-Butron and Artibai-Urdaibai in which $F_{\mathrm{ST}}$ values were statistically significant, suggesting that some restriction in gene flow occurs between them. The greatest levels of differentiation were observed between feral and ranch mink and the differentiation increased with distance of the site from the farm (Table 3). Similar results were obtained using the harmonic mean $D_{\text {est }}$ index which was low between mink trapping sites (ranging from 0.0001 to 0.05 ) but very high between mink from trapping sites and mink from the farm (ranging between 0.08 and 0.20 ; Table 3 ).

The Bayesian model-based clustering analysis implemented in STRUCTURE indicated the presence of two genetic clusters in this sample of American mink. Although the $K=2$ model did not have the absolute maximal posterior probability $(\operatorname{Ln} P(D))$ value, this model was supported by the highest $\Delta K$ value (267) where the $\Delta K$ value for $K$ between 3 and 6 ranged from 0.2 to 25 . This analysis, implying the likely presence of two genetically distinct groups and the assignment of individuals to populations for $K=2$, is presented in Fig. 3. The individuals caught at the five sampling sites were assigned to one cluster and all individuals from the farm were assigned to the other cluster (Fig. 3). The feral and ranch mink had very high average membership values (q) ranging from 80 to $99 \%$ for the feral cluster and $99 \%$ for the ranch cluster. Individuals from the Artibai river (the closest site to the farm) had the lowest assignments $(80 \%)$ because 2 out of $12(17 \%)$ of the individuals assigned to the ranch mink cluster with very high q values (0.984 and 0.997$)$, which implies that they might be escapees from the farm. Both individuals were caught $7 \mathrm{~km}$ from the farm.

Table 3 Pairwise $F_{\mathrm{ST}}$ estimates (above diagonal) and harmonic mean estimates $D_{\text {est }}$ across loci (below diagonal) among American mink samples taken from five river catchments and one farm (ranch) in N Spain

\begin{tabular}{llllllr}
\hline Sampling site & Ibaizabal & Butron & Urdaibai & Lea & Artibai & Ranch \\
\hline Ibaizabal & - & 0.0019 & 0.0077 & 0.0119 & 0.0350 & $\mathbf{0 . 1 2 9 0}$ \\
Butron & 0.0001 & - & 0.0082 & 0.0220 & $\mathbf{0 . 0 4 5 2}$ & $\mathbf{0 . 1 4 7 2}$ \\
Urdaibai & 0.0013 & 0.0016 & - & 0.0038 & $\mathbf{0 . 0 5 1 1}$ & $\mathbf{0 . 1 3 0 8}$ \\
Lea & 0.0013 & 0.0089 & 0.0007 & - & 0.0420 & $\mathbf{0 . 0 9 0 0}$ \\
Artibai & 0.0114 & 0.0290 & 0.0518 & 0.0187 & - & $\mathbf{0 . 0 8 2 1}$ \\
Ranch & 0.1706 & 0.2012 & 0.1869 & 0.1322 & 0.0797 & - \\
\hline
\end{tabular}

Bold indicated $P<0.05$ 


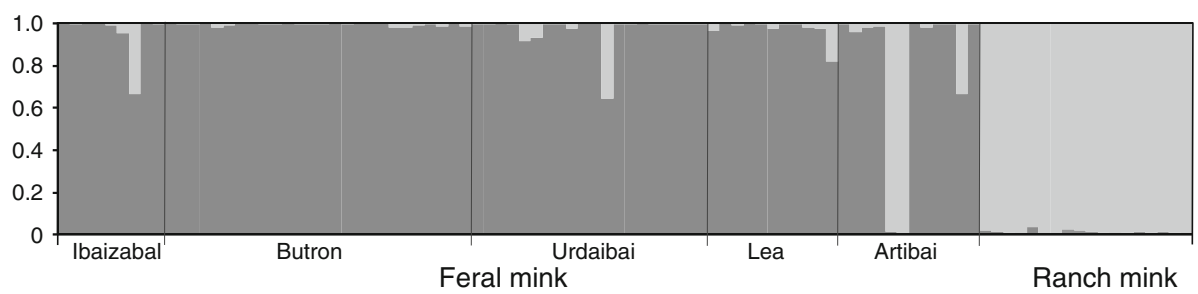

Fig. 3 Proportional membership of each American mink in the two clusters identified by STRUCTURE. Each American mink is represented by a single vertical bar. The locality of origin for each individual is indicated below
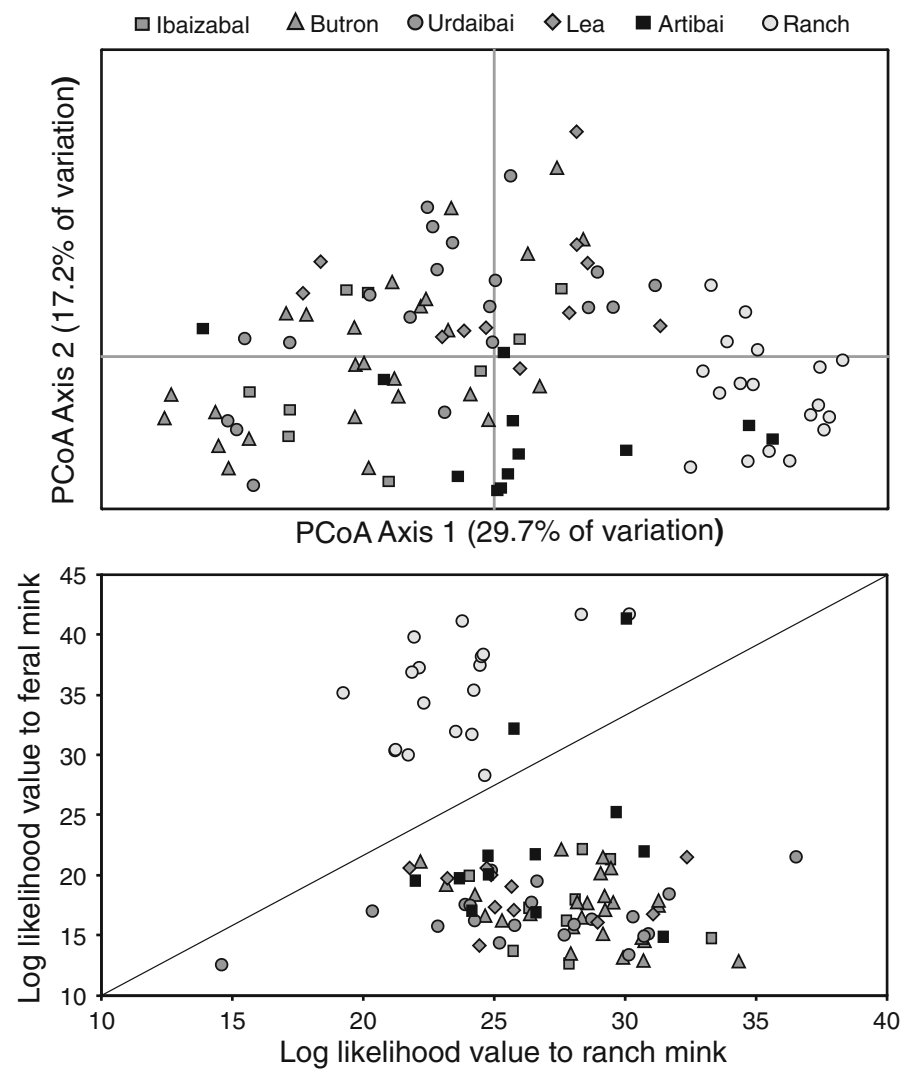

Fig. 4 Principal coordinates analysis of individuals from 5 river catchments and one mink farm (upper panel) and genetic assignment to feral and ranch mink of individuals captured in these river catchments and at the farm (lower panel)

Population genetic substructure and membership was further evaluated by using the population assignment and PCA of individual American mink (Fig. 4). Assignment tests showed that 65 mink $(97 \%)$ caught in the wild were assigned to the feral population, whereas 2 mink ( $3 \%$ ) were assigned to ranch mink. Simultaneously, the 18 mink from the farm $(100 \%)$ were correctly assigned to the ranch population. The PCA performed using 


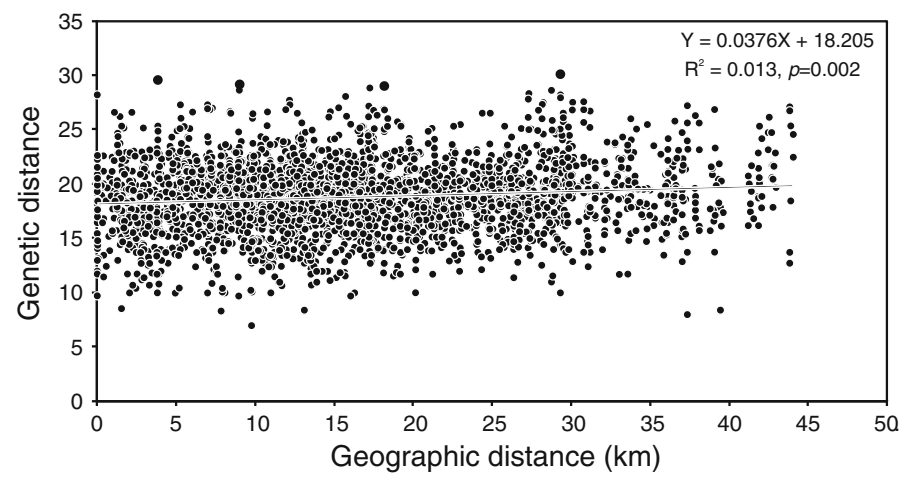

Fig. 5 Correlation between genetic and geographic distance (the Euclidean distance in $\mathrm{km}$ ) among all pairs of feral American mink individuals in Biscay

individual mink genotypes identified discrete clusters (Fig. 4). PCA Axis 1 and 2 accounted for $51.4 \%$ (34.7 and $16.7 \%$, respectively) of the total variation (Fig. 4). Axis 1 of the PCA separated feral and ranch individuals but feral individuals from different sites were scattered over the graph revealing a high degree of overlap between sites (Fig. 4). Two individuals from the Artibai site were assigned to ranch mink.

The isolation-by-distance analysis (Mantel test) shows a very weak, but significant, positive relationship between geographical and genetic distances (Fig. 5). When individuals from Artibai which were an admixture with ranch mink were excluded from analyses this relationship was not significant (analyses did not show). Fine-scale spatial autocorrelation analyses further resolved the scale of spatial structuring among feral American mink. The autocorrelation coefficient ( $\mathrm{r}$ ) was significantly positive over a distance of $5 \mathrm{~km}$, showing that spatial genetic structure was detected only for this distance (Fig. 6).

River variables affecting mink population

The average home range of male European mink in the study area was found to be $13 \mathrm{~km}$ of river. This was the largest home range, when considering the two species and the two genders (Kruskal-Wallis test, $H=9.290, P=0.026$, df $=3$; Table 2).

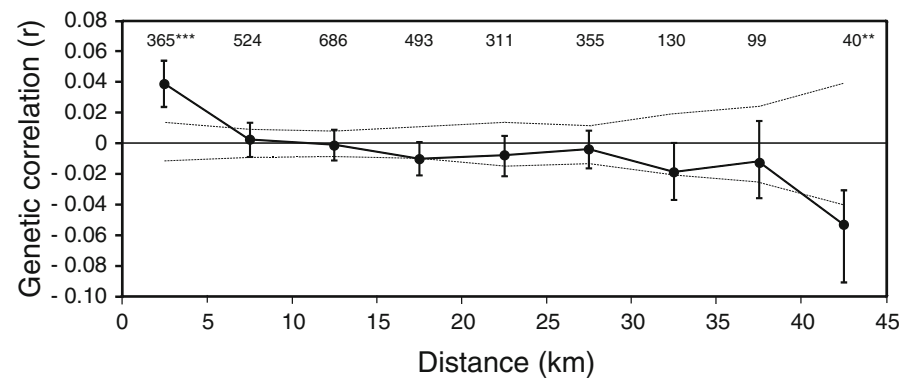

Fig. 6 Spatial genetic structure for feral American mink pairwise individuals in Biscay (Basque Country, Northern Spain). The permutation $95 \%$ confidence interval (dashed lines) and the bootstrapped $95 \%$ confidence error bars are also shown. The numbers of pairwise comparisons within each distance class is presented above the plotted values. Stars indicate statistically significant spatial autocorrelation values $(* * P<0.01, * * * P<0.001)$ 
The presence of European mink depends on the non-fragmented main river stretches and the number of tributaries free from barriers (see table 4). The best models (model 5 and 7 in table 5) also selected these variables: non-fragmented main river stretches $(\beta=-$ $0.001 \pm 0.0003$, wald $=5.981, P=0.014)$ and tributaries without barriers $(\beta=-$ $0.303 \pm 0.136$, wald $=4.987, P=0.026$ ). The positive cases of American mink (19) in the buffer area show a less demanding habitat selection than European mink, although the univariate statistics showed similar requirements for both species (Table 4) and a negative effect caused by moderate tributary barriers (model 6), none of these variables were statistically significant in the model. Only one variable, the number of tributaries free from barriers was close to the significance $(\beta=-0.186 \pm 0.099$, wald $=3.382, P=0.06)$. Considering both species together, model 6 was again the best model and the number of tributaries free from barriers was the unique significant variable in it $(\beta=-$ $0.285 \pm 0.119$, wald $=5.750, P=0.016$ ).

\section{Discussion}

Habitat fragmentation, caused by various types of barriers, leads to the isolation of populations and an associated increase in genetic differentiation due to restricted gene flow and/or genetic drift (Frankham et al. 2002). Additionally, in invasive species, the genetic structure is often well developed due to founder effect (Zeisset and Beebee 2003; Rollins et al. 2009; Zalewski et al. 2010). A high level of genetic structure has been observed, even in extremely mobile predators such as American mink, in cases where they inhabit fragmented landscape (Lecis et al. 2008; Zalewski et al. 2010, 2011). However, in our current study, Bayesian clustering methods did not detect genetic structure and $F_{\mathrm{ST}}$ values were low and not significant, indicating that there is a high level of gene flow of feral American mink between catchments. In addition, assignment tests and PCA methods did not separate the feral mink which came from different catchments. All these results indicate a high degree of connectivity of American mink among catchments, even when considering those which are farthest apart and separated by mountain ranges (Butrón and Artibai, $33 \mathrm{~km}$ ). It is highly possible that American mink could move easily from one catchment to another, since the distance between the upper streams of two different catchments is usually less than $1 \mathrm{~km}$. This closeness is most evident in winter, when rivers are swollen. Mink can then move along the river bed to the top of small streams, subsequently crossing to the other side of the mountain by walking through forest, heather or grassland. In fact we detected several records of American and European mink found relatively far away from rivers whilst walking between two basins (i.e. Zuberogoitia and Zabala, 2003b). Therefore, whilst mountains may slow down the spread of mink, they do not act as absolute barriers to broad-scale movement (Zalewski et al. 2009).

All genetic analyses ( $F_{\mathrm{ST}}$, Bayesian clustering, assignment test and PCA) show that the feral population which colonised the study area is genetically different to the ranch mink kept on the one existing farm which is located near the study area. Furthermore, the genetic variability of feral mink was much lower than that of ranch mink, which backs up the results of previous studies (Michalska-Parda et al. 2009; Zalewski et al. 2010, 2011). Escapees from the farm were recorded at the Artibai river and they increased the genetic variability of mink caught at this river. The effective number of alleles and also the number of private alleles found in mink caught on this river were the highest of all the study sites of feral mink. 


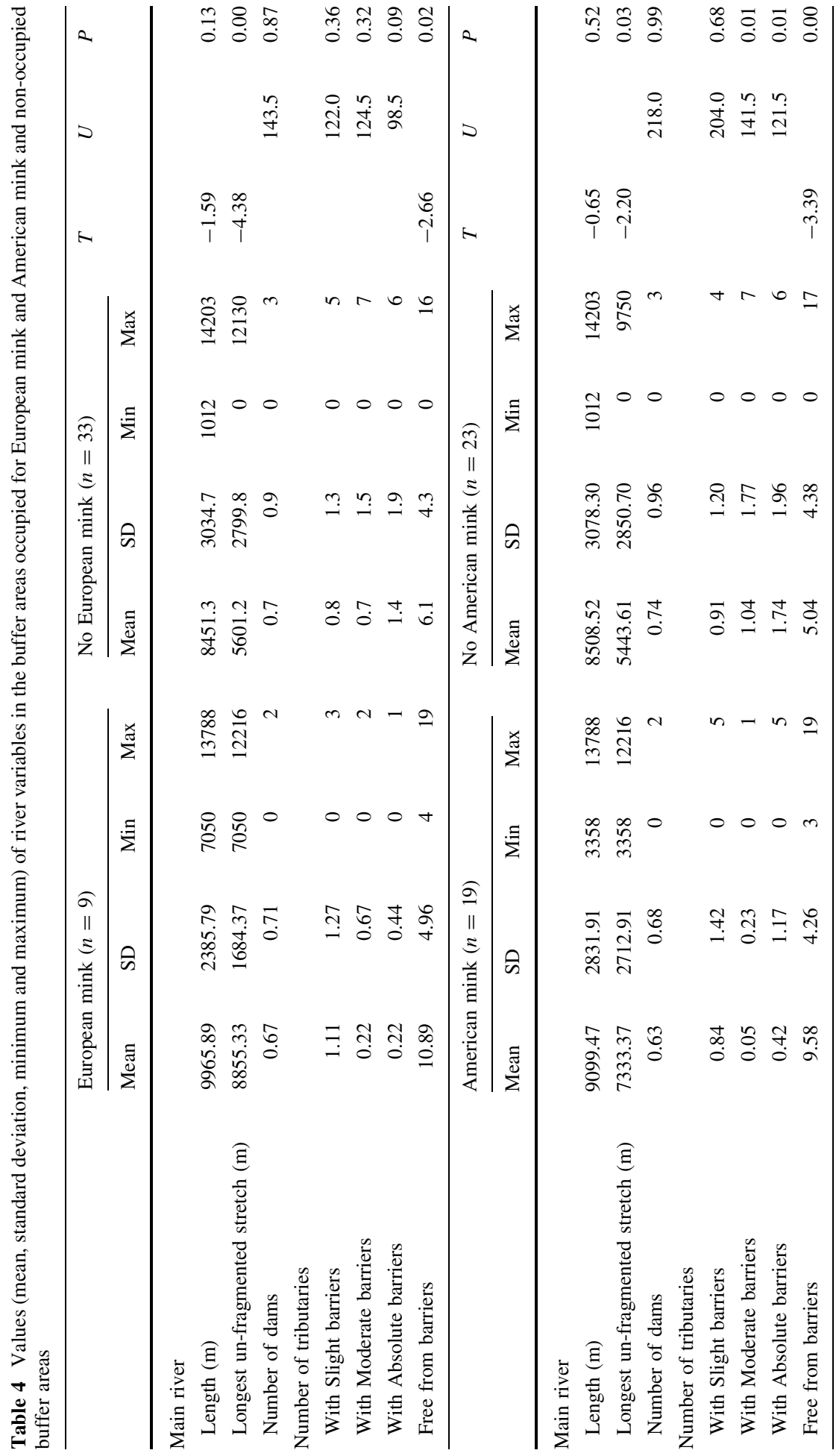




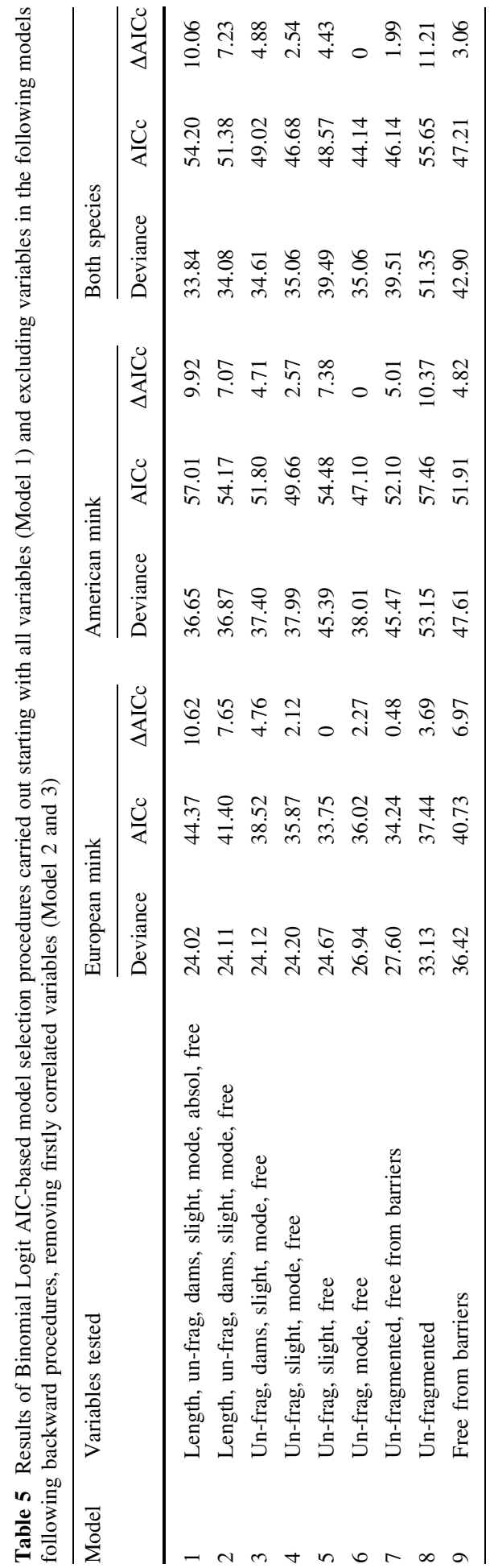


Our results confirm our suspects that the mink population established on Butrón River at the beginning of the 1990s may be the origin of almost all the feral mink population of the study area (Zuberogoitia and Zabala 2003a). However, the colonisation process seemed to be slow, possibly due to the large number of geographic and anthropogenic barriers. The first observation made after Butrón was recorded in the neighbouring catchment of Urdaibai (the main river central points are $15 \mathrm{~km}$ apart) five years later, in 1995, and over the next ten years American mink became abundant in the Urdaibai basin. With the colonisation of the area by American mink and the increase in their population, a decrease in numbers of European mink was observed. During a mink survey carried out in 1999-2000 in the Urdaibai catchment, we captured 11 European mink and no American mink (trapping effort = 1,609 trap-nights; Garin et al. 2002b), whilst in the winter of 2008-2009, i.e. after the invasion had occurred, we captured 13 American mink and only 3 European mink (trapping effort $=1,233$ trap-nights). Obviously American mink displaced European mink and occupied the same habitat. European mink populations collapsed, probably due to intraguild competition between the two species (see Maran et al. 1998; Sidorovich et al. 2010).

On the other hand our models show that, besides the competition, the presence of barriers on the rivers and tributaries also has an effect on European and American mink occurrence within the study area. Both mink occurred more frequently on those river stretches which had the lowest number of barriers than in random locations, although European mink is probably more affected by habitat fragmentation than American mink, which seems to be more adaptable. In fact, the best model to explain European mink presence after AICc included the number of slight barriers as a explanatory variable whilst models for the American mink did not. This suggests that while American mink can cope with slight barriers and small dams in their territories, European mink are more affected by their negative effects. Mink can cross most of the barriers and can reach some highly altered streams but there are no long, good-quality, barrier-free stretches which facilitate persistence for long periods in these catchments. The high number of barriers and the high fragmentation level prevent populations from becoming established. The length of main river stretches between two fragmented areas and the low number of tributaries which are free from barriers are insufficient to meet the habitat requirements of one male mink (Zabala et al. 2006). It is possible to detect mink in these rivers which could have arrived from neighbouring areas but the odds of trapping the incoming mink are very low, since their occurrence is only temporary. In fact, although these types of river fragments can be occupied for a short time, the high risk rate and the low flux of floaters classify them as merely sink patches for mink. We detected several deaths on the roads along the valley bottoms of highly-fragmented rivers.

\section{Conclusion}

Our results provide evidence that habitat fragmentation reduces the persistence of riparian predators. Despite the fact that mink may cross barriers and that the whole population is connected, as shown by the lack of any genetic structure in the population, there are large areas which are not occupied by either mink species, as a consequence of severe fragmentation. Although American mink have been considered to be one of the worst influences on the European mink population, river fragmentation could also have a strong negative impact on this endangered species. Moreover, the generalist species suffer 
fragmentation, but in lesser extent, and then they can survive better in fragmented landscapes and can be in advantage against similar specialized species, such as European mink.

Despite the cost and effort of control/eradication projects (see Zabala et al. 2010) their eventual success will not guarantee a recovery of European mink populations because of the deleterious effects of habitat fragmentation.

Acknowledgments The trapping projects were supported and monitored by the Conservation, Natura 2000 Network and Biodiversity Service of the Department of Agriculture of the County Council of Biscay, following a European Mink Monitoring Program (County Order 118/2006 June19th). We are grateful to A. Azkona and C. Rodríguez-Refojos for their field assistance in the 2007-2008 trapping season and to the Fish and Game rangers who trapped during the 2009-2011 trapping seasons (A. Alava, J. Aguirre, E. Díaz, A. Egia, J.R. Egia, M. Eguizabal, G. Etxabe, A. Galarza, E. Garamendi, L. González, E. Goikolea, A. Goñi, A. Jaureguizar, K. Llaguno, F. Martínez, A. Oregi, J.M. Pérez de Ana, J. Ruíz, D. Rodríguez, J.M. Sagarna, M. San Sebastián and J. Santiesteban). The comments by two anonymous referees helped us to improve a previous version of the manuscript. We also thank A. Farrell for linguistic revision.

Open Access This article is distributed under the terms of the Creative Commons Attribution License which permits any use, distribution, and reproduction in any medium, provided the original author(s) and the source are credited.

\section{References}

Anistoroaei R, Farid A, Benkel B, Cirera S, Christensen K (2006) Isolation and characterization of 79 microsatellite markers from the American mink (Mustela vison). Anim Genet 37:185-188

Battin J (2004) When good animals love bad habitats: ecological traps and the conservation of animal populations. Conserv Biol 18:1482-1491

Brusgaard K, Shukri N, Malchenko SN, Lohi O, Christensen K, Kruse T (1998) Three polymorphic mink, Mustela vison, dinucleotide repeats. Anim Genet 29:153

Burnham KP, Anderson DR (2002) Model selection and multi-model inference: a practical informationtheoretic approach. Springer, Berlin

Crawford NG (2010) smogd: software for the measurement of genetic diversity. Mol Ecol Resour 10:556-557

Department of Environment and Land Ordination (2001) Medio Ambiente en la Comunidad Autónoma del País Vasco. Basque Government Press, Vitoria-Gasteiz

Evanno G, Regnaut S, Goudet J (2005) Detecting the number of clusters of individuals using the software STRUCTURE: a simulation study. Mol Ecol 14:2611-2620

Fahrig L (2003) Effects of habitat fragmentation on biodiversity. Ann Rev Ecol Evol Syst 34:487-515

Farid A, Vincent IR, Benkel BF, Christensen K (2004) Isolation of microsatellite markers for American mink (Mustela vison). Scientifur 28:228-233

Felton AM, Engstrom LM, Felton A, Knott CD (2003) Orangutan population density, forest structure and fruit availability in hand-logged and unlogged peat swamp forests in West Kalimantan, Indonesia. Biol Conserv 114:91-101

Fischer J, Lindenmayer DB (2007) Landscape modification and habitat fragmentation: a synthesis. Global Ecol and Biogeogr 16:265-280

Fleming MA, Ostrander EA, Cook JA (1999) Microsatellite markers for American mink (Mustela vison) and ermine (Mustela erminea). Mol Ecol 8:1351-1362

Frankham R, Ballou JD, Briscoe DA (2002) Introduction to conservation genetics. Cambridge University Press, Cambridge

Garin I, Aihartza J, Zuberogoitia I, Zabala J (2002a) Activity pattern of European mink (Mustela lutreola) in Southwestern Europe. Z Jagdwiss 48:102-106

Garin I, Zuberogoitia I, Zabala J, Aihartza J, Clevenger A, Rallo A (2002b) Home range of European mink Mustela lutreola in southwestern Europe. Acta Theriol 47:55-62

Goudet J (1995) FSTAT (Version 1.2): A computer program to calculate F-statistics. J Heredity 86:485-486 
Hazell D, Hero JM, Lindenmayer D, Cunningham R (2004) A comparison of constructed and natural habitat for frog conservation in an Australian agricultural landscape. Biol Conserv 119:61-71

Jager HI, Carr EA, Efroymson RA (2006) Simulated effects of habitat loss and fragmentation on a solitary mustelid predator. Ecol Model 191:416-430

Jost L (2008) G(ST) and its relatives do not measure differentiation. Mol Ecol 17:4015-4026

Kruuk H (2006) Otters. Ecology, behaviour and conservation. Oxford University Press, Great Britain

Lecis R, Ferrando A, Ruiz-Olmo I, Manas S, Domingo-Roura X (2008) Population genetic structure and distribution of introduced American mink (Mustela vison) in Spain, based on microsatellite variation. Conserv Genet 9:1149-1161

Lodé T, Peltier D (2005) Genetic neighbourhood and effective population size in the endangered European mink Mustela lutreola. Biodivers Conserv 14:251-259

Lodé T, Cornier JP, Le Jacques D (2001) Decline in endangered species as an indication of anthropic pressures: the case of European mink Mustela lutreola western population. J Environ Manage 28:221-227

Macdonald DW, Sidorovich VE, Maran T, Kruuk H (2002) European Mink, Mustela lutreola: Analyses for conservation. Wildlife Conservation Research Unit, Oxford

Macpherson JL, Bright PW (2010) Movements of radio-tracked American mink in extensive wetland in the $\mathrm{UK}$, and the implications for threatened prey species such as the water vole. Eur J Wildl Res 56:855-859

Malanson GP (1993) Riparian landscapes. Cambridge University Press, Cambridge

Maran T, Macdonald DW, Kruuk H, Sidorovich V, Rozhnov VV (1998) The continuing decline of the European mink Mustela lutreola: evidence for the intraguild aggression hypothesis. In: Dunston N, Gorman ML (eds) Behaviour and ecology of riparian mammals. Symposium of the Zoological Society of London, vol 71. Cambridge University Press. Cambridge, pp 297-323

Melero Y, Palazón S, Revilla E, Martelo J, Gosalbez J (2008) Space use and habitat preferences of the invasive American mink (Mustela vison) in a Mediterranean area. Eur J Wildl Res 54:609-617

Michalska-Parda A, Brzezinski M, Zalewski A, Kozakiewicz M (2009) Genetic variability of feral and ranch American mink Neovison vison in Poland. Acta Theriol 54:1-10

Moors PJ (1980) Sexual dimorphism in the body size of mustelids (Carnivora): the roles of food habits and breeding systems. Oikos 34:147-158

Mortelliti A, Amori G, Boitani L (2010) The role of habitat quality in fragmented landscapes: a conceptual overview and prospectus for future research. Oecologia 163:535-547

Navarro C (1980) Contribución al estudio de la flora y vegetación del Duranguesado y la Busturia. Universidad Complutense de Madrid, Master thesis

O'Connell M, Wright JM, Farid A (1996) Development of PCR primers for nine polymorphic American mink Mustela vison microsatellite loci. Mol Ecol 5:311-312

Peakall R, Smouse PE (2006) GENALEX 6: genetic analysis in Excel. Population genetic software for teaching and research. Mol Ecol Notes 6:288-295

Peakall R, Ruibal M, Lindenmayer DB (2003) Spatial autocorrelation analysis offers new insights into gene flow in the Australian bush rat, Rattus fuscipes. Evolution 57:1182-1195

Petts GE (1984) Impounded rivers: perspectives for ecological management. Wiley, Chichester

Pritchard JK, Stephens M, Donnelly P (2000) Inference of population structure using multilocus genotype data. Genetics 155:945-959

Raymond M, Rousset F (1995) Genepop (version-1.2)—population-genetics software for exact tests and ecumenicism. J Heredity 86:248-249

Rollins LA, Woolnough AP, Wilton AN, Sinclair R, Sherwin WB (2009) Invasive species can't cover their tracks: using microsatellites to assist management of starling (Sturnus vulgaris) populations in Western Australia. Mol Ecol 18:1560-1573

Schüttler E, Ibarra JT, Gruber B, Rozzi R, Jax K (2010) Abundance and habitat preferences of the southernmost population of mink: implications for managing a recent island invasion. Biodivers Conserv 19:725-743

Sidorovich VE, Polozov AG, Zalewski A (2010) Food niche variation of European and American mink during the American mink invasion in north-eastern Belarus. Biol Invasions 12:2207-2217. doi: 10.1007/s10530-009-9631-0

Smouse PE, Peakall R (1999) Spatial autocorrelation analysis of individual multiallele and multilocus genetic structure. Heredity 82:561-573

Van Oosterhout C, Hutchinson WF, Wills DPM, Shipley P (2004) MICRO-CHECKER: software for identifying and correcting genotyping errors in microsatellite data. Mol Ecol Notes 4:535-538

Vincent IR, Farid A, Otieno CJ (2003) Variability of thirteen microsatellite markers in American mink (Mustela vison). Can J Anim Sci 83:597-599 
Virgos E (2001) Relative value of riparian woodlands in landscapes with different forest cover for mediumsized Iberian carnivores. Biodivers Conserv 10:1039-1049

Zabala J, Zuberogoitia I (2003) Habitat use of male European mink (Mustela lutreola) during the activity period in south western Europe. Z Jagdwiss 49:77-81

Zabala J, Zuberogoitia I, Garin I, Aihartza J (2003) Landscape features in the habitat selection of European mink (Mustela lutreola) in south-western Europe. J Zool London 260:1-7

Zabala J, Zuberogoitia I, Martínez JA (2006) Factors affecting occupancy by the European mink in SouthWestern Europe: a predictive model for evaluating the incidente of biotic and abiotic factors as a tool for setting management and conservation guidelines. Mammalia 3:193-201

Zabala J, Zuberogoitia I, Martínez JA (2007a) Winter habitat preferences of feral American mink Mustela vison Schreber, 1777 in Biscay (Northern Iberian Peninsula). Acta Theriol 52:27-36

Zabala J, Zuberogoitia I, Martínez JA (2007b) Spacing pattern, intrasexual competition and niche segregation in American Mink. Ann Zool Fenn 44:249-258

Zabala J, Zuberogoitia I, González-Oreja JA (2010) Estimating costs and outcomes of invasive American mink (Neovison vison) management in continental areas: a framework for evidence based control and eradication. Biol Invasions 12:2999-3012

Zalewski A, Piertney SB, Zalewska H, Lambin X (2009) Landscape barriers reduce gene flow in an invasive carnivore: geographical and local genetic structure of American mink in Scotland. Mol Ecol 18:1601-1615

Zalewski A, Michalska-Parda A, Bartoszewicz M, Kozakiewicz M, Brzeziński M (2010) Multiple introductions determine the genetic structure of an invasive species population: American mink Neovison vison in Poland. Biol Conserv 143:1355-1363. doi:10.1016/j.biocon.2010.03.009

Zalewski A, Michalska-Parda A, Ratkiewicz M, Kozakiewicz M, Bartoszewicz M, Brzeziński M (2011) High mitochondrial DNA diversity of an introduced alien carnivore: comparison of feral and ranch American mink Neovison vison in Poland. Divers Distrib 17:757-768. doi:10.1111/j.1472-4642. 2011.00767.x

Zar J (1996) Biostatistical analysis, 3rd edn. Prentice Hall, New Jersey

Zeisset I, Beebee TJC (2003) Population genetics of a successful invader: the marsh frog Rana ridibunda in Britain. Mol Ecol 12:639-646

Zuberogoitia I, Zabala J (2003) Aproximación a la distribución del Visón Americano en Bizkaia. Galemys 15(1):29-35

Zuberogoitia I, Zabala J (2003b) Does European Mink use only rivers or do they also use other habitats? Small Carnivore Conserv 28:7-8

Zuberogoitia I, Zabala J, Martínez JA (2006) Diurnal activity and observations of the hunting and ranging behaviour of the American mink (Mustela vison). Mammalia 70:310-312

Zuberogoitia I, González-Oreja JA, Zabala J, Rodríguez-Refojos C (2010) Assessing the control/eradication of an invasive species, the American mink, based on field data; how much would it cost? Biodivers Conserv 19:1455-1469 